\title{
Influence of Interferon beta treatment on quality of life in multiple sclerosis patients
}

Isabella Laura Simone*1, Antonia Ceccarelli ${ }^{1}$, Carla Tortorella1, Alessandra Bellacosa ${ }^{1}$, Fabio Pellegrini ${ }^{2}$, Immacolata Plasmati ${ }^{1}$, Maria Fara De Caro ${ }^{1}$, Mariangela Lopez ${ }^{1}$, Francesco Girolamo ${ }^{1}$ and Paolo Livrea ${ }^{1}$

\author{
Address: ${ }^{1}$ Department of Neurological and Psychiatric Sciences, University of Bari, Italy and ${ }^{2}$ Department of Clinical Pharmacology and \\ Epidemiology, Istituto di Ricerche Farmacologiche Mario Negri, Consorzio Mario Negri Sud, Santa Maria Imbaro, Italy \\ Email: Isabella Laura Simone* - isasimone@neurol.uniba.it; Antonia Ceccarelli - ceccarelli.antonella@hsr.it; \\ Carla Tortorella - carla.tortorella@libero.it; Alessandra Bellacosa - bellacosa@libero.it; Fabio Pellegrini - pellegrini@negrisud.it; \\ Immacolata Plasmati - immaplasmati@libero.it; Maria Fara De Caro - mf.decaro@neurol.uniba.it; Mariangela Lopez - lopez@libero.it; \\ Francesco Girolamo - f.girolamo@histology.uniba.it; Paolo Livrea - plivrea@neurol.uniba.it \\ * Corresponding author
}

Published: 12 December 2006

Health and Quality of Life Outcomes 2006, 4:96 doi:10.1 186/1477-7525-4-96

This article is available from: http://www.hqlo.com/content/4/1/96

(c) 2006 Simone et al; licensee BioMed Central Ltd.

This is an Open Access article distributed under the terms of the Creative Commons Attribution License (http://creativecommons.org/licenses/by/2.0), which permits unrestricted use, distribution, and reproduction in any medium, provided the original work is properly cited.
Received: 04 August 2006

Accepted: 12 December 2006

\begin{abstract}
Background: Interferon-beta (IFN- $\beta$ ) shows beneficial effect on the course of multiple sclerosis (MS), nevertheless its route and frequency of administration and side effects might impact negatively the quality of life (QoL) of MS patients. The objective of this study was to evaluate the influence of IFN- $\beta$ on $\mathrm{Q} o \mathrm{~L}$ in MS patients.
\end{abstract}

Methods: Seventy-seven disease modifying treatment (DMT) free and 4 I IFN- $\beta$ treated MS patients were evaluated. QoL, assessed by MSQoL-54, was related to IFN- $\beta$ treatment and to clinical and demographic parameters at baseline and after two years. Multivariate hierarchical linear model for repeated measurements was used.

Results: Treated patients showed a younger age, a lower disease duration and a higher relapse rate in the two years preceding study entry. At inclusion time treated and untreated patients did not differ in relapse rate, expanded disability status scale (EDSS), fatigue, depression, physical and mental QoL. IFN- $\beta$ did not influence QoL at inclusion time, but when QoL was evaluated after two years, treatment negatively affected mental QoL. Depression and fatigue negatively influenced physical and mental QoL both at baseline and after two years. EDSS correlated with a poor physical QoL only at baseline.

Conclusion: IFN- $\beta$ had a negative impact on QoL over the time in MS patients, influencing mainly mental QoL. The impairment of QoL in MS was strongly associated with increasing fatigue and depression, whereas clinical disability had a minor unfavourable role. 


\section{Background}

In the last years increasing interest focused on QoL instrument as a broader measure of the burden of MS. Recent studies reported that QoL assessment may provide unique information often underestimated by the EDSS [1-3], which remains to date the primary clinical outcome measure for MS related disability [4]. Several factors may influence the QoL in MS patients. Previous studies showed varying results on the relationship between neurological disability and impaired QoL, suggesting only a partial contribute of disability on QoL. On the contrary fatigue and depression are highly associated to a poor QoL [5$11]$.

Although the QoL instrument is recommended as an outcome measure of therapeutic choices and treatment effectiveness, its use is still limited in the routine clinical approaches [12]. Patient's perspectives derived from lifelong treatment, as well as adherence to prolonged therapies and side-related effects are often underestimated. Some authors reported a beneficial influence of IFN- $\beta$ therapy on QoL $[13,14]$. Nevertheless, adverse effects related to treatment may negatively impact QoL $[14,15]$.

The objective of this study was to determine the influence over the time of IFN- $\beta$ treatment on QoL in MS patients.

\section{Methods \\ Patients}

A non-randomized study was performed on 127 consecutive patients followed at MS centre of the Department of Neurological and Psychiatric Sciences of the University of Bari. The patients were enrolled over three months. At inclusion time, QoL was evaluated in all patients. After two years further assessment of QoL was proposed to the same patients: 93 out of 127 completed the MS QoL questionnaire, whereas 34 patients refused. Seventy-seven of 127 patients were DMT free and not eligible for immunosuppressive or immunomodulatory therapies during the following two years. Forty-one patients were assuming IFN- $\beta$ from $3.6 \pm 1.9$ months at inclusion: 30 patients IFN- $\beta$ 1a (14 Avonex ${ }^{\circledast}$ and 16 Rebif $\left.^{\circledast}\right)$ and 11 patients IFN$\beta$ 1b. No patient stopped treatment during two years of follow-up. Finally 9 of 127 patients started to assume IFN$\beta$ at different time during the study. This latter group was excluded from the analysis, since the relative low number of patients and the limited use of the drug might be confounding factors for statistical evaluation.

All patients had definite MS, according to Mc Donald criteria [16]. Exclusion criteria were current or past history of psychiatric disorders, clinical relapse or corticosteroids drugs in the last three months preceding the observation. No patient needed anti-depressive treatment for the whole period of the study. The study was conducted with local ethical committee approval and with patients written informed consent.

\section{Measures}

In all patients clinical disability was measured by the EDSS [4]. Quality of life was assessed by MSQoL-54 instrument developed by Vickrey et al [17] and validated in an Italian population by Solari at al [18]. The scale consists of 54 items that are distributed in 12 multi-item scales and 2 single item scales. The instrument includes questions from Short Form 36-Item Health Survey as a generic core measure [19] and 18 additional items specific for MS exploring health distress, sexual function, overall quality of life, cognitive function and energy. Physical and mental health composite scores are calculated as a weighted sum of selected domains to generate a simplified two-dimension solution to MSQoL-54 instrument.

The subscales for the physical health composite summary are: physical function, health perceptions, energy, role limitation-physical, bodily pain, social function and health distress. The subscales for the mental health composite summary are: overall quality of life, emotional well being, role limitation-emotional, cognitive function and health distress. The composite scores range from 0 (poor health) to 100 (optimal health).

Fatigue severity scale (FSS) consists of nine questions, ranging from 1 (low fatigue) to 7 (high fatigue) with a suggested cut-off point of 4.5 [20]. Depression status was assessed using the Beck Depression Inventory (BDI) consisting of 21 items self-report rating inventory [21]. Cognitive functions were evaluated by Mini Mental State Examination corrected with school-attendance index (MMSE-c) [22].

MSQoL-54, FSS and BDI were self-administered in the presence of an assistant if required by the patients.

\section{Statistical analysis}

Patients' baseline characteristics in treated and untreated groups were compared using Pearson $\chi^{2}$ for categorical variables and t-student test for continuous variables.

Baseline and changes after two years in clinical items and QoL scores were expressed as mean \pm standard deviation (SD). T-student test was used to assess differences between treated and untreated groups at baseline and after two years of follow-up for all continuous measures. Each MSQoL-54 component (physical and mental composite score and relative scales) was analysed with a multivariate hierarchical linear model for repeated measurements [23]. Hierarchical linear models are particularly suited for repeated measurements analysis dealing with unbalanced designs (i.e. presence of drop-outs). These models allow 
to simultaneously assess the impact of baseline and timevarying covariates on QoL baseline scores and their changes over time, and also to evaluate, via interaction terms with the time variable, the impact of baseline covariates over time.

For each QoL component the baseline covariates were: age at inclusion, gender (male vs. female), disease duration, disease course (secondary progressive, SP vs. relapsing remitting, RR), relapse rate in the two years preceding the study entry, EDSS, BDI, FSS, MMSE-c and IFN- $\beta$ treatment (IFN- $\beta$ treated vs. untreated groups). Changes in time-varying covariates are expressed as difference between two years follow-up and baseline assessment. The impact of changes in relapse rate, EDSS, BDI, FSS and MMSE-c on changes in QoL scores and the effect of treatment group over the time were also evaluated.

As to baseline variables, $\beta$ parameters for continuous covariates represent the difference in QoL score for each unit increase in the covariate, and $\beta$ s for categorical covariates indicate the difference in QoL for each category respect to the reference one. As to other variables, $\beta$ s for time-varying covariates refer to QoL changes for each unit change in the covariate over the two years of follow-up, and $\beta$ s for time and treatment-by-time interaction indicate QoL changes over the two years of follow-up in treated and untreated groups. P-values $<0.05$ were considered significant.

Further, drop-out mechanism was analysed to assess the extent of informative missing data due to patients who did not complete the questionnaire after two years of follow-up [24]. All the analyses were performed using SAS Statistical Package Release 9.1 (SAS Institute, Cary, NC).

\section{Results}

Table 1 reports baseline demographic and disease related patient characteristics according to treatment group. A prevalence of RR course and female gender characterized each group, without any statistical difference. Untreated patients showed a significant higher age at inclusion $(\mathrm{p}=$ $0.02)$ and a longer disease duration $(p=0.04)$ in comparison to treated patients. At baseline MS groups did not differ in EDSS, BDI, FSS, physical, mental health composite scores as well as relative scales. Relapse rate in the two years before study entry was significantly higher in IFN- $\beta$ treated patients $(\mathrm{p}<0.0001)$ (Table 2$)$. After two years of follow-up mental health composite score $(\mathrm{p}=0.006)$ and emotional well being score $(\mathrm{p}=0.014)$ significantly decreased in IFN- $\beta$ treated group (Table 2).

Results of multivariate hierarchical analysis are summarized in Table 3, 4, 5. At baseline a poor physical health composite score was significantly associated with a higher age at inclusion ( $\mathrm{p}=0.043)$ and higher EDSS, FSS and BDI scores $(p<0.0003)$. A lower mental health composite score was correlated to increased BDI $(\mathrm{p}<0.0001)$ and FSS score $(p=0.019)$. Other unfavourable factors were the male gender $(p=0.005)$ and RR course $(p=0.037)$. As expected, almost all QoL scales related to the physical composite score showed a negative association with EDSS and FSS score. All mental QoL scales were mainly related to impaired BDI (Table 4 and 5). Treatment did not influence physical and mental composite scores and relative subscales at baseline (Table 3, 4, 5).

At Follow-up, worsening in physical and mental QoL health composite scores (Table 3) and in most of their subscales (Table 4 and 5) were significantly associated to higher BDI and FSS scores. Changes in EDSS did not influence all QoL subscales, except for physical function ( $\mathrm{p}=$ 0.003 ). When considering the impact of the treatment on QoL after two years, the untreated patients did not show statistical changes in physical and mental health composite score. The IFN- $\beta$ treated group showed a worsening in physical composite score and in most of their relative subscales, even if it was not significant. In this group mental health composite score significantly worsened over two years $(p=0.01)$. In addition emotional well being $(p=$ $0.03)$ and health distress $(p=0.03)$ showed significant negative changes.

Thirty-four patients (28.8\%) did not complete the QoL questionnaire at two years follow-up: 27 belonged to untreated and 7 to treated group. The assessment of informative drop-outs did not show significant differences in all the clinical and QoL measures at baseline between drop-outs and completers (data not shown).

\section{Discussion}

To our knowledge, this study is the first to evaluate the influence of the therapy on QoL by multivariate hierarchical analysis and the first to demonstrate a poor QoL in relation to IFN- $\beta$ treatment.

At inclusion time treated MS patients showed a younger age, a lower disease duration and a higher relapse rate in the two years before study entry in comparison to untreated group. This latter finding could be explained by the short period of the treatment at study entry, and in turn it represented the reason of starting the treatment. However, the used statistical analysis adjusted for all clinical and demographic inter-group differences. Previous short and long term IFN- $\beta$ studies indicated a positive influence of the treatment on physical QoL $[14,26,27]$ and mental QoL [28]. Moreover MS patients showed a good performance in mental QoL domains, also independently on the treatment $(29,30)$. In our study shortterm treatment did not influence physical and mental 
Table I: Baseline characteristics in untreated and treated MS groups

\begin{tabular}{lcccc}
\hline \multicolumn{1}{c}{ Variable } & Covariate & Untreated & IFN- $\beta$ treated & p-value \\
\hline No. of patients & & 77 & 41 & $28.7 \pm 10.5$ \\
Age at disease onset (yrs) & & $30.3 \pm 9.7$ & $36.8 \pm 11.5$ & 0.42 \\
Age at inclusion (yrs) & Male & $28.1 \pm 11.2$ & $3(19.5)$ & $\mathbf{0 . 0 2}$ \\
Gender & Female & $49(63.6)$ & $33(80.5)$ & 0.06 \\
Disease duration (yrs) & & $12.0 \pm 7.8$ & $8.9 \pm 8.1$ & 0.04 \\
Disease course & RR & $58(75.3)$ & $74(82.9)$ & 0.34 \\
School education (degree- & SP & $19(24.7)$ & $6(17.1)$ & 0.97 \\
yrs) & $<5$ & $10(12.9)$ & $7(17.1)$ & $19(46.3)$ \\
& $6-8$ & $16(21)$ & $9(22)$ \\
\end{tabular}

Data are expressed as means \pm SD or $n$ (\%). P-values refer to $T$ test or Pearson $\chi^{2}$.

QoL. In fact no differences in QoL scores were found between untreated and treated patients. After two years we observed a slight, even if not significant, worsening in physical QoL in treated patients, and this was in agreement with another report [31]. The main finding of our analysis was the negative influence of IFN- $\beta$ treatment on mental health composite score and in most of its relative subscales QoL over the time.

In accordance with several authors fatigue and depression are undoubtedly significant predictors of a poor QoL, affecting both physical and mental domains, even after adjusting for all other clinical factors $[6,8,10,11,32]$. Although fatigue and depression may be considered the most frequent side effects during IFN therapy, we found that their impact on QoL was independent on the therapy, since FSS and BDI scores did not differ in treated and untreated patients. Furthermore changes in fatigue and depression over time induced a progressive worsening of QoL.

Clinical disability at inclusion was related to a poor physical QoL $[1,6-8,11,30]$, but its negative influence was not as much as expected [29]. In fact changes in EDSS over the time did not impact significantly QoL measures. Disease duration did not affect the QoL, whereas a higher age at inclusion was significantly related to a poor physical composite score as well as to physical function, role limitation

Table 2: Time-varying covariates. Means \pm SD at baseline and change after 2-years follow-up in untreated and treated MS groups

\begin{tabular}{|c|c|c|c|c|c|c|}
\hline \multirow[b]{2}{*}{ Time-varying covariates } & \multicolumn{2}{|c|}{ Untreated n. 77} & \multicolumn{2}{|c|}{ IFN- $\beta$ treated $n .4$ I } & \multicolumn{2}{|c|}{ p-value* } \\
\hline & Baseline & Change & Baseline & Change & Baseline & Change \\
\hline Relapse rate ${ }^{* *}$ & $0.2 \pm 0.3$ & $0.0 \pm 0.4$ & $0.7 \pm 0.5$ & $-0.1 \pm 0.6$ & $<0.0001$ & 0.37 \\
\hline EDSS & $3.1 \pm 1.7$ & $0.4 \pm 0.8$ & $3.0 \pm 1.8$ & $0.4 \pm 1.1$ & 0.84 & 0.93 \\
\hline BDI & $9.5 \pm 7.7$ & $1.3 \pm 10.3$ & $10.8 \pm 9.2$ & $2.2 \pm 9.8$ & 0.57 & 0.88 \\
\hline FSS & $2.5 \pm 1.8$ & $1.1 \pm 1.7$ & $2.8 \pm 1.9$ & $1.2 \pm 1.8$ & 0.53 & 0.75 \\
\hline MMSE-c & $28.5 \pm 2.0$ & $-0.6 \pm 2.4$ & $28.1 \pm 3.7$ & $-0.5 \pm 2.5$ & 0.78 & 0.70 \\
\hline \multicolumn{7}{|l|}{ MSQoL-54 Measures } \\
\hline Physical health composite score & $65.5 \pm 21.4$ & $-5.5 \pm 17.2$ & $65.1 \pm 22.3$ & $-9.1 \pm 18.9$ & 0.91 & 0.45 \\
\hline Mental health composite score & $69.1 \pm 19.8$ & $1.2 \pm 20.2$ & $71.6 \pm 18.2$ & $-12.1 \pm 19.1$ & 0.54 & 0.006 \\
\hline Physical function & $67.7 \pm 35.8$ & $-2.3 \pm 14.7$ & $69.5 \pm 35.4$ & $-8.8 \pm 19.1$ & 0.80 & 0.13 \\
\hline Health perceptions & $47.5 \pm 23.4$ & $-3.0 \pm 23.1$ & $48.7 \pm 22.7$ & $-6.0 \pm 26.9$ & 0.76 & 0.64 \\
\hline Energy & $47.7 \pm 22.6$ & $1.1 \pm 23.0$ & $47.0 \pm 23.0$ & $-1.2 \pm 23.0$ & 0.91 & 0.57 \\
\hline Role limitation-physical & $67.6 \pm 43.5$ & $-4.6 \pm 42.9$ & $65.2 \pm 40.7$ & $-|4.3 \pm 4| .8$ & 0.48 & 0.52 \\
\hline Bodily pain & $79.7 \pm 25.7$ & $-8.7 \pm 30.9$ & $74.0 \pm 29.7$ & $-8.1 \pm 28.6$ & 0.39 & 0.41 \\
\hline Sexual function & $83.1 \pm 26.6$ & $-6.0 \pm 35.6$ & $81.5 \pm 27.0$ & $-12.0 \pm 36.5$ & 0.67 & 0.62 \\
\hline Social function & $74.2 \pm 23.3$ & $-5.8 \pm 23.4$ & $74.4 \pm 21.3$ & $-10.0 \pm 21.5$ & 0.87 & 0.49 \\
\hline Health distress & $70.8 \pm 23.0$ & $-2.0 \pm 31.6$ & $71.9 \pm 20.4$ & $-13.3 \pm 24.0$ & 0.98 & 0.06 \\
\hline Overall quality of life & $67.5 \pm 19.0$ & $-1.0 \pm 22.3$ & $64.4 \pm 18.8$ & $-8.6 \pm 24.3$ & 0.46 & 0.17 \\
\hline Cognitive function & $78.6 \pm 20.6$ & $-0.4 \pm 23.0$ & $82.4 \pm 20.6$ & $-12.2 \pm 23.9$ & 0.31 & 0.06 \\
\hline Emotional well-being & $57.1 \pm 22.8$ & $5.4 \pm 43.2$ & $59.5 \pm 16.7$ & $-21.6 \pm 42.5$ & 0.65 & 0.014 \\
\hline Role limitation- emotional & $70.6 \pm 43.3$ & $0.4 \pm 27.2$ & $78.9 \pm 36.3$ & $-6.4 \pm 21.0$ & 0.37 & 0.22 \\
\hline Satisfation with sexual function & $60.4 \pm 26.7$ & $2.0 \pm 34.9$ & $54.3 \pm 30.6$ & $-3.7 \pm 37.0$ & 0.33 & 0.40 \\
\hline Change in health & $47.1 \pm 19.9$ & $0.5 \pm 21.3$ & $50.6 \pm 22.7$ & $4.6 \pm 35.5$ & 0.43 & 0.36 \\
\hline
\end{tabular}

*p-values refer to t-test between treated and untreated groups at baseline and after 2 years follow-up.

**Relapse rate was evaluated in the 2 -years preceding study entry (baseline)and after 2 years of follow-up (change) 
Table 3: Predictors of MSQoL-54 composite scores by IFN- $\beta$ treatment (Multivariate hierarchical analysis)

\begin{tabular}{|c|c|c|c|c|}
\hline \multirow[b]{2}{*}{ Effect } & \multicolumn{2}{|c|}{ Physical Health Composite Score } & \multicolumn{2}{|c|}{ Mental Health Composite Score } \\
\hline & $\beta$ & $p$ & $\beta$ & $p$ \\
\hline Intercept* & 65.08 & $<.0001$ & 69.31 & $<.0001$ \\
\hline Age at inclusion & -0.19 & 0.043 & -0.22 & 0.06 \\
\hline Gender (Male vs. Female) & $-|.5|$ & 0.43 & -6.95 & 0.005 \\
\hline Disease duration & -0.1 & 0.41 & -0.04 & 0.82 \\
\hline Disease course (SP vs. RR) & 3.69 & 0.24 & 8.39 & 0.037 \\
\hline Relapse rate 2-yrs before study entry & 0.69 & 0.75 & 0.62 & 0.83 \\
\hline EDSS & -3.44 & 0.0003 & -0.85 & 0.47 \\
\hline BDI & -0.59 & $<.0001$ & -1.44 & $<.0001$ \\
\hline FSS & -6.69 & $<.0001$ & -2.08 & 0.019 \\
\hline MMSE-c & -0.28 & 0.44 & 0.45 & 0.34 \\
\hline IFN- $\beta$ treatment (Yes vs No) & -0.09 & 0.97 & 2.75 & 0.36 \\
\hline Relapse rate change after 2-yrs & 2.15 & 0.42 & 0.60 & 0.84 \\
\hline EDSS change after 2 -yrs & -1.57 & 0.26 & 1.59 & 0.31 \\
\hline BDI change after 2-yrs & -0.60 & $<.0001$ & -1.08 & $<.0001$ \\
\hline FSS change after 2-yrs & -5.21 & $<.0001$ & -2.48 & 0.01 \\
\hline MMSE-c change after 2-yrs & -0.35 & 0.53 & -0.16 & 0.81 \\
\hline Time** & 1.32 & 0.54 & 3.33 & 0.19 \\
\hline Time $\times$ IFN- $\beta$ treatment (Yes vs No) & -1.65 & 0.58 & -9.19 & 0.01 \\
\hline
\end{tabular}

*Intercept value represents the baseline mean score for reference group (Untreated)

**Time value represents the mean score change for reference group (Untreated) after 2 years of follow-up

physical, bodily pain and cognitive function. Previous studies reported lower QoL score in SP in comparison to RR MS $(6,29,32)$. In contrast, we found that RR course negatively influenced QoL. In our MS population the SP course was much less frequent than RR course and this might contribute to a bias in the analysis.

Certainly the relative short period of follow-up, in comparison to previous longer longitudinal studies, may represent a possible limitation of the present study. [30].
Further analysis in a larger number of treated patients is required in order to evaluate the influence of frequency and route of administration of IFN- $\beta$ s

\section{Conclusion}

In conclusion this study showed that treatment with IFN$\beta$ had a negative impact on QoL over the time in MS patients, influencing in particular the mental composite score. On the contrary, short-term treatment did not affect the QoL. Depression and fatigue were confirmed as main

Table 4: Predictors of Physical health MSQoL-54 scales by IFN- $\beta$ treatment (Multivariate hierarchical analysis)

\begin{tabular}{|c|c|c|c|c|c|c|c|c|c|c|c|c|}
\hline \multirow[b]{2}{*}{ Effect } & \multicolumn{2}{|c|}{ Energy } & \multicolumn{2}{|c|}{ Health perceptions } & \multicolumn{2}{|c|}{ Physical function } & \multicolumn{2}{|c|}{ Role limitation physical } & \multicolumn{2}{|c|}{ Bodily pain } & \multicolumn{2}{|c|}{ Social function } \\
\hline & $\beta$ & $P$ & $\beta$ & $P$ & $\beta$ & $\mathrm{P}$ & $\beta$ & $\mathrm{P}$ & $\beta$ & $P$ & $\beta$ & $P$ \\
\hline Intercept* & 45.11 & $<.0001$ & 44.67 & $<.0001$ & 69.40 & $<.0001$ & 71.72 & $<.0001$ & 74.23 & $<.0001$ & 72.54 & $<.0001$ \\
\hline Age at inclusion & -0.12 & 0.36 & 0.06 & 0.68 & -0.4 & 0.01 & -0.60 & 0.03 & -0.36 & 0.04 & 0.06 & 0.66 \\
\hline Gender (Male vs. Female) & -0.51 & 0.84 & 2.00 & 0.52 & 1.07 & 0.75 & -17.3 & 0.003 & 3.74 & 0.31 & -0.32 & 0.90 \\
\hline Disease duration & -0.02 & 0.92 & -0.36 & 0.08 & 0.10 & 0.64 & 0.19 & 0.60 & -0.38 & 0.12 & -0.30 & 0.10 \\
\hline Disease course (SP vs. RR) & 9.54 & 0.03 & 7.35 & 0.16 & -8.44 & 0.12 & 8.77 & 0.34 & 17.33 & 0.004 & 8.65 & 0.06 \\
\hline Relapse rate 2-yrs before study entry & 0.37 & 0.90 & -2.01 & 0.58 & 0.70 & 0.86 & 1.39 & 0.83 & -0.20 & 0.96 & 3.76 & 0.24 \\
\hline EDSS & -2.33 & 0.06 & -3.54 & 0.02 & -8.44 & $<.0001$ & -4.69 & 0.09 & -2.82 & 0.11 & -2.65 & 0.05 \\
\hline BDI & -1.16 & $<.0001$ & -0.26 & 0.20 & 0.25 & 0.26 & -0.92 & 0.01 & 0.22 & 0.36 & -0.66 & 0.0004 \\
\hline FSS & -4.80 & $<.0001$ & -6.8 & $<.0001$ & -8.69 & $<.0001$ & -10.0 & $<.0001$ & -9.74 & $<.0001$ & -6.72 & $<.0001$ \\
\hline MMSE-c & -0.19 & 0.71 & -0.43 & 0.46 & 0.05 & 0.94 & -1.90 & 0.10 & 0.02 & 0.98 & -0.30 & 0.57 \\
\hline IFN- $\beta$ treatment (Yes vs No) & 1.43 & 0.65 & 3.56 & 0.32 & 1.20 & 0.77 & 5.03 & 0.50 & 4.54 & 0.32 & 0.23 & 0.94 \\
\hline Relapse rate change after 2-yrs & 4.96 & 0.17 & 2.40 & 0.61 & 3.76 & 0.20 & $-2.7 \mid$ & 0.69 & 2.96 & 0.54 & 6.77 & 0.08 \\
\hline EDSS change after 2-yrs & -0.11 & 0.95 & -1.49 & 0.54 & -4.54 & 0.003 & 0.59 & 0.86 & 0.70 & 0.77 & -2.72 & 0.16 \\
\hline BDI change after 2-yrs & -0.67 & 0.0005 & -0.48 & 0.05 & -0.14 & 0.37 & -1.59 & $<.0001$ & -0.82 & 0.002 & -0.67 & 0.001 \\
\hline FSS change after 2-yrs & -5.20 & $<.0001$ & -4.89 & 0.001 & -4.65 & $<.0001$ & -4.75 & 0.03 & -5.98 & 0.0001 & -4.39 & 0.0003 \\
\hline MMSE-c change after 2-yrs & -1.09 & 0.15 & 0.20 & 0.84 & -0.10 & 0.87 & -3.04 & 0.04 & -0.64 & 0.53 & 0.18 & 0.81 \\
\hline Time** & 8.67 & 0.004 & 3.36 & 0.37 & -4.84 & 0.05 & -1.00 & 0.86 & -1.81 & 0.65 & 0.64 & 0.84 \\
\hline Time $\times$ IFN- $\beta$ treatment (Yes vs No) & -0.76 & 0.86 & -1.72 & 0.74 & -6.15 & 0.07 & -2.54 & 0.77 & 3.82 & 0.50 & -1.73 & 0.69 \\
\hline
\end{tabular}

*Intercept value represents the baseline mean score for reference group (Untreated)

**Time value represents the mean score change for reference group (Untreated) after 2 years of follow-up 
Table 5: Predictors of Mental health MSQoL-54 scales by IFN- $\beta$ treatment (Multivariate hierarchical analysis)

\begin{tabular}{|c|c|c|c|c|c|c|c|c|c|c|}
\hline \multirow[b]{2}{*}{ Effect } & \multicolumn{2}{|c|}{ Emotional well being } & \multicolumn{2}{|c|}{ Role limitation emotional } & \multicolumn{2}{|c|}{ Health distress } & \multicolumn{2}{|c|}{ Cognitive function } & \multicolumn{2}{|c|}{ Overall quality of life } \\
\hline & $\beta$ & $P$ & $\beta$ & $P$ & $\beta$ & $P$ & $\beta$ & $P$ & $\beta$ & $P$ \\
\hline Intercept* & 73.6 & $<.0001$ & 53.68 & $<.0001$ & 69.6 & $<.0001$ & 78.3 & $<.0001$ & 68.6 & $<.0001$ \\
\hline Age at inclusion & -0.31 & 0.32 & -0.11 & 0.45 & 0.08 & 0.57 & -0.41 & 0.01 & 0.02 & 0.86 \\
\hline Gender (Male vs. Female) & -19.83 & 0.003 & 1.68 & 0.57 & -3.69 & 0.19 & -8.55 & 0.01 & -4.05 & 0.14 \\
\hline Disease duration & -0.29 & 0.49 & 0.13 & 0.50 & 0.08 & 0.69 & -0.16 & 0.49 & 0.13 & 0.49 \\
\hline Disease course (SP vs. RR) & 15.2 & 0.15 & 8.75 & 0.08 & 4.21 & 0.37 & 14.8 & 0.008 & -2.55 & 0.57 \\
\hline Relapse rate 2-yrs before study entry & -0.31 & 0.97 & 0.15 & 0.96 & -0.31 & 0.92 & -0.40 & 0.92 & -1.40 & 0.66 \\
\hline EDSS & 1.15 & 0.71 & -2.13 & 0.14 & -0.11 & 0.93 & -0.70 & 0.67 & $-1.5 \mid$ & 0.25 \\
\hline BDI & -1.50 & $<.0007$ & -1.86 & $<.0001$ & -1.75 & $<.0001$ & -1.01 & $<.0001$ & -1.35 & $<.0001$ \\
\hline FSS & -8.33 & $<.0005$ & 1.67 & 0.12 & -2.86 & 0.005 & -1.06 & 0.38 & 0.02 & 0.98 \\
\hline MMSE-c & 0.15 & 0.91 & 0.42 & 0.44 & 0.84 & 0.11 & 1.69 & 0.009 & 0.39 & 0.46 \\
\hline IFN- $\beta$ treatment (Yes vs No) & 7.67 & 0.34 & 5.22 & 0.13 & 4.99 & 0.13 & 3.12 & 0.44 & -1.16 & 0.73 \\
\hline Relapse rate change after 2-yrs & -4.36 & 0.57 & 3.64 & 0.39 & -1.90 & 0.72 & 2.90 & 0.51 & -3.34 & 0.35 \\
\hline EDSS change after 2-yrs & 2.95 & 0.44 & -1.32 & 0.54 & 1.57 & 0.56 & 3.09 & 0.17 & -0.24 & 0.89 \\
\hline BDI change after 2-yrs & -1.65 & $<.0001$ & -1.20 & $<.0001$ & -0.84 & 0.003 & -0.91 & .0001 & -1.15 & $<.0001$ \\
\hline FSS change after 2-yrs & -3.63 & 0.13 & -1.14 & 0.38 & -3.66 & 0.02 & -0.20 & 0.88 & -2.65 & 0.02 \\
\hline MMSE-c change after 2-yrs & -1.29 & 0.42 & 0.58 & 0.50 & 1.42 & 0.20 & 0.04 & 0.97 & -1.40 & 0.6 \\
\hline Time** & 5.68 & 0.37 & 5.31 & 0.11 & 4.15 & 0.32 & -0.64 & 0.86 & 0.31 & 0.91 \\
\hline Time $\times$ IFN- $\beta$ treatment (Yes vs no) & -19.11 & 0.03 & -4.95 & 0.27 & -12.29 & 0.03 & -9.65 & 0.05 & 2.53 & 0.54 \\
\hline
\end{tabular}

*Intercept value represents the baseline mean score for reference group (Untreated)

**Time value represents the mean score change for reference group (Untreated) after 2 years of follow-up

predictors of a poor QoL, whereas clinical disability had a minor unfavourable impact. In planning interventions for MS, psychological components of patients have to be always taken into account. Prospective studies in a larger sample of MS patients are required to enhance the evidence of the drug impact on QoL [33].

\section{Competing interests}

All authors give no competing financial and non-financial interests to declare

\section{Authors' contributions}

ILS conceived and coordinated the study and drafted the manuscript; AC participated in the study design and helped to draft the manuscript; CT participated in the study design and helped to draft the manuscript; $A B$ carried out the clinical evaluation; FP carried out the statistical analysis; IP carried out the clinical evaluation; MFD carried out the neuropsychological evaluation; ML carried out the neuropsychological evaluation; FG carried out the clinical evaluation; PL contributed to design the study

\section{Acknowledgements}

This study was supported by MIUR-PRIN 2004 grant n. 2004063800_02 and Cesare Serono Foundation.

\section{References}

I. Nortvedt MW, Riise T, Myhr KM, Nyland HI: Quality of life in multiple sclerosis: measuring the disease effects more broadly. Neurology 1999, 53:1098-1103.

2. The Canadian Burden of Illness Study Group: Burden of illness of multiple sclerosis. II. Quality of life. Can J Neurol Sci 1998, 25:3I-38.

3. Nortvedt MW, Riise T: The use of quality of life measures in multiple sclerosis research. Mult Scler 2003, 9:63-72.

4. Kurtzke JF: Rating neurological impairment in multiple sclerosis: An expanded disability status scale (EDSS). Neurology 1983, 33: | 444-1452.
5. Shawaryn MA, Schiaffino KM, LaRocca NG, Johnston MV: Determinants of health-related quality of life in multiple sclerosis: the role of illness intrusiveness. Mult Scler 2002, 8:310-318.

6. Amato MP, Ponziani G, Rossi F, Liedl CL, Stefanile C, Rossi L: Quality of life in multiple sclerosis: the impact of depression, fatigue and disability. Mult Scler 200I, 7:340-344.

7. Zivadinov R, Zorzon M, Tommasi MA, Nasuelli D, Bernardi M, MontiBragadin L, Cazzato G: A longitudinal study of quality of life and side effects in patients with multiple sclerosis treated with interferon beta-Ia. J Neurol Sci 2003, 216: I 33-II8.

8. Patti F, Capocardo M, Palermo F, Ciancio MR, Lopes R, Restivo D, Reggio A: Health-related quality of life and depression in an Italian sample of multiple sclerosis patients. J Neurol Sci 2003, 21 1:55-62.

9. Janssen ACJW, van Doorn PA, de Boer JB, Kalkers NF, van der Mechè FCA, Passchier J: Anxiety and depression influence the relation between disability status and quality of life in multiple sclerosis. Mult Scler 2003, 9:397-403.

10. Lobentanz IS, Asenbaum S, Vass K, Sauter C, Klosch G, Kollegger H, Ristoferitsch W, Zeitlhofer J: Factors influencing quality of life in multiple sclerosis patients, depressive mood, fatigue and sleep quality. Acta Neurol Scand 2004, I I 0:6-13.

II. Benedict RHB, Wahlig E, Bakshi R, Fishman I, Munschauer F, Zivadinov $R$, Weinstock-Guttman B: Predicting quality of life in multiple sclerosis: accounting for physical disability, fatigue, cognition, mood disorder, personality, and behavior change. J Neurol Sci 2005, 23 I:29-34.

12. Mitchell AJ, Benito-León J, Moralez-Gonzales JM, Rivera-Navarro J: Quality of life and its assessment in multiple sclerosis: integrating physical and psychological components of wellbeing. Lancet Neurol 2005, 4:556-566.

13. Rice GP, Oger J, Duquette P, Francis GS, Belanger M, Laplante S, Grenier JF: Treatment with interferon beta- I $b$ improves quality of life in multiple sclerosis. Can J Neurol Sci 1999, 26:276-282.

14. Arnoulds JHA, Kilestein J, Pfennings L, Jelles B, Uitdehaag BMJ, Polman $\mathrm{CH}$ : Quality of life during the first 6 months of interferon- $\beta$ treatment in patients with MS. Mult Scler 2000, 6:338-342.

15. Nortvedt MW, Riise T, Myhr KM, Nyland HI, Hanestad BR: Type I interferons and the quality of life of multiple sclerosis patients. Results from a clinical trial on interferon alfa-2a. Mult Scler 1999, 5:317-322.

16. McDonald WI, Compston A, Edan G, Goodkin D, Hartung HP, Lublin FD, McFarland HF, Paty DW, Polman CH, Reingold SC, SandbergWollheim M, Sibley W, Thompson A, van den Noort S, Weinshenker BY, Wolinsky JS: Recommended diagnostic criteria for multiple sclerosis: guidelines from International Panel on the diagnosis of multiple sclerosis. Ann Neurol 200I, 50:2I-I 27. 
17. Vickrey BG, Hays RD, Harooni R, Meyers LW, Elfison GW: A health-related quality of life measure for multiple sclerosis. Qual Life Res 1995, 4:187-206.

18. Solari A, Filippini G, Mendozzi L, Ghezzi A, Cifani S, Barbieri E, Baldini S, Salmeggi A, La Mantia L, Farinotti M, Caputo D, Mosconi P: Validation of italian multiple sclerosis quality of life 54 questionnaire. J Neurol Neurosurg Psychiatry 1999, 67:158-162.

19. Ware JE, Sherbourne CD: A 36-item short-form health survey (SF-36): I. Conceptual framework and item selection. Med Care 1992, 30:473-483.

20. Krupp LB, La Rocca NG, Muir-Nash J, Steinberg AD: The fatigue severity scale. Application to patients with multiple sclerosis and systemic lupus erythematosus. Arch Neurol 1989, 46: II2I-III24.

2I. Beck AT, Ward CH, Mendelson M, Mock JE, Erbaugh JK: An inventory for measuring depression. Arch Gen Psychiatry 1961, 4:56I-57I.

22. Measso G, Cavarzeran F, Zappalà G, Lebowitz BD, Crook TH, Pirizzolo $\mathrm{F}$ : The mini-mental state examination: normative study of an Italian random sample. Dev Neuropsychol 1993, 9:77-85.

23. Singer JD, Willett JB: Applied Longitudinal Data Analysis: Modeling Change and Event Occurrence. New York: Oxford University Press; 2003.

24. Diggle PJ, Liang KY, Zeger SL: Analysis of Longitudinal Data. Oxford: Oxford University Press; 1994.

25. Gottberg K, Garduf A, Fredrikson S: Interferon-beta treatment for patients with multiple sclerosis: the patients' perceptions of the side-effects. Mult Scler 2000, 6:349-354.

26. Freeman JA, Thompson AJ, Fitzpatrick R, Hutchinson M, Miltenburger C, Beckmann K, Dahlke F, Kappos L, Polman C, Pozzilli C, European Study Group Interferon-beta Ib in Secondary Progressive MS: Interferon- $\beta \mathrm{Ib}$ in the treatment of secondary progressive MS. Impact on quality of life. Neurology 200I, 57:1870-I875.

27. Cohen JA, Cutter GR, Fischer JS, Goodman AD, Heidenreich FR, Kooijmans MF, Sandrock AW, Rudick RA, Simon JH, Simonian NA, Tsao EC, Whitaker JN, IMPACT Investigators: Benefit of interferon $\beta$-Ia on MSFC progression in secondary progressive MS. Neurology 2002, 59:679-687.

28. Isaksson AK, Ahlström G, Gunnarsson LG: Quality of life and impairment in patients with multiple sclerosis. J Neurol Neurosurg Psychiatry 2005, 76:64-69.

29. Pittock SJ, Mayr WT, McClelland RL, Jorgensen NW, Weigand SD, Noseworthy JH, Rodriguez M: Quality of life is favorable for must patients with multiple sclerosis. Arch Neurol 2000 61:679-686.

30. Solari A, Ferrari G, Radice D: A longitudinal survey of selfassessed health trends in a community cohort of people with multiple sclerosis and their significant others. J Neurol Sci 2006 243: $13-20$

31. Vermersch P, de Seze J, Delisse B, Lemaire S, Stojkovic T: Quality of life in multiple sclerosis: influence of interferon-betal a (Avonex) treatmen. Mult Scler 2002, 8:377-38I.

32. Janardhan V, Baskshi R: Quality of life in patients with multiple sclerosis: The impact of fatigue and depression. J Neurol Sci 2002, 205:5I-58.

33. Fisk JD, Brown MG, Sketris IS, Metz LM, Murray TJ, Stadnyk KJ: A comparison of health utility measures for the evaluation of multiple sclerosis treatments. J Neurol Neurosurg Psychiatry 2005, 76:58-63.
Publish with Biomed Central and every scientist can read your work free of charge

"BioMed Central will be the most significant development for disseminating the results of biomedical research in our lifetime. "

Sir Paul Nurse, Cancer Research UK

Your research papers will be:

- available free of charge to the entire biomedical community

- peer reviewed and published immediately upon acceptance

- cited in PubMed and archived on PubMed Central

- yours - you keep the copyright

Submit your manuscript here:

http://www.biomedcentral.com/info/publishing_adv.asp
BioMedcentral 